Hagberg B et al. Late onset globoid cell leukoencephalopathy (Krabbe's disease) - Swedish case with 15 years of follow-up. Acta Paediatr Feb

$1995 ; 84: 218-21)$. The disease presented with visual dysfunction at 4 years of age. At 8 years he developed a limp and ataxia and within 6 months he was wheel-chair dependent. Epilepsy began at 14 years. Speech became dysarthric on entering school, but he was able to stay in the mainstream educational system. Leukocyte galactosylceramidase activity was reduced.

\title{
CONGENITAL LACTIC ACIDOSIS: PET AND MRS STUDIES
}

Positron emission tomography (PET) and proton magnetic resonance spectroscopy (MRS) identified an increase in rate of cerebral glycolysis (PET) and cerebral lactate (MRS) in 2 children with defective mitochondrial respiration and congenital lactic acidosis studied at the Universitat zu Koln, Germany, and the University Hospital, Nijmegen, The Netherlands. These changes were not apparent in a child with lactic acidosis and normal respiratory chain activity. Defects of oxidative phosphorylation may cause increases in glycolysis and accumulation of cerebral lactate. (Duncan DB et al. Positron emission tomography and magnetic resonance spectroscopy of cerebral glycolysis in children with congenital lactic acidosis. Ann Neurol March 1995;37:351-358). (Respond: Prof Dr Heiss, Max-Planck-Institut fur neurologische Forschung, Gleueler Str 50, 50931 Koln, Germany).

COMMENT. PET and MRS have been used to demonstrate the metabolic changes associated with defective mitochondrial respiration in the brain without resort to diagnostic muscle biopsy. For further discussion of MRS in mitochondrial disorders, see Progress in Pediatric Neurology II, 1994, p454.

\section{VASCULAR DISORDERS}

\section{NEONATAL MIDDLE CEREBRAL ARTERY STROKE}

The presentation, EEG, imaging studies, and outcome of six term neonates with middle cerebral artery infarcts are reported from Mannheim Hospital, University of Heidelberg, Germany. Birth was by cesarean section in 5 cases. Apgars were normal in 4. Seizures occurred in 4 within 1 to 3 days and in 2 at the 5 th and 9th days. EEGs showed focal slowing followed by focal spikewave activity, correlating with the structural lesion defined by neuroimaging. EEG abnormalities sometimes antedated a positive ultrasound. A late intrauterine event was suggested. Only 2 had obvious hemiparesis at discharge, but all children showed developmental delay and spastic hemiparesis at 3 to 10 year follow up. One had infantile spasms and hemihypsarrhythmia, relieved only after drainage of a cyst and shunt procedure. Four developed epilepsy late. (Koelfen W, Freund M, Varnholt V. Neonatal stroke involving the middle cerebral artery in term infants: Clinical presentation, EEG and imaging studies, and outcome. Dev Med Child Neur March 1995;37:204-212). (Respond: Dr Wolfgang Koelfen, Kinderklinik Mannheim, Theodor Kutzer Ufer, 68127 Mannheim, Germany).

COMMENT. This study confirms previous reports of late onset of epilepsy and development of spastic hemiparesis and cognitive deficits following an apparent early favorable outcome in term neonates suffering middle 